\title{
Taxa de infiltração de água no solo em diferentes usos do solo
}

\author{
Milton Cesar Delgado de Almeida Júnior ${ }^{\mathrm{a}}$, Patrícia Alves Leão de Castro ${ }^{\mathrm{a}}{ }^{\oplus}$, Gilmar Oliveira Santos ${ }^{\mathrm{a}^{*}(\mathbb{0}}$ \\ ${ }^{\text {a }}$ Universidade de Rio Verde, Brasil \\ *Autor correspondente (gilmar@unirv.edu.br)
}

\section{N F O}

\section{Keywords}

fertigation

swine manure

notillage

\section{Palavras-chaves}

fertirrigação

dejeto suíno

plantio direto

\begin{abstract}
A B S T R A C T
Soil water infiltration rate in different soil uses

Understanding the Water Infiltration Rate (RIW) in the soil is essential to determine the runoff and infiltration of water in the soil. The objective of this work was to compare the RIW in an area with and without application of swine manure and in Permanent Preservation Areas on top of a hill (APPt) and close to the riverbed (APPs) on agricultural property in the municipality of Rio Verde, Goiás. He used the Kostiakov model to determine RIW. The physical and chemical quality of the soil and the effluent were analyzed. There was a low concentration of nutrients and sodium adsorption ratio in swine manure. The irrigated areas where the soil was clayey and very high RIW, infiltration rates ranged from 114 to $69 \mathrm{~mm}$ $\mathrm{h}^{-1}$, for areas with and without manure, respectively. APPs presented sandy soils with RIW ranging from 210 to $384 \mathrm{~mm} \mathrm{~h}^{-1}$ in APPt and APPs, respectively. The soil management technique used in the agricultural area, no-till or fertigation, and the areas with native vegetation, in sedimentary soil or not, provided compaction and, consequently, higher RIW in the soil.
\end{abstract}

\section{R E S U M O}

O entendimento da Taxa de Infiltração de Água (TIB) no solo é fundamental para determinar o escoamento e infiltração de água no solo. O objetivo deste trabalho foi comparar a TIB em uma área com e sem aplicação de dejeto suíno e em Áreas de Preservação Permanente em topo de morro (APPt) e próximo ao leito do rio (APPs) em propriedade agricultável no município de Rio Verde, Goiás. Utilizou o modelo de Kostiakov para determinar a TIB. Analizou-se a qualidade física e química do solo e do efluente. Houve baixa concentração de nutrientes e razão de adsorção de sódio no dejeto suíno. As áreas irrigadas onde o solo era argiloso e TIB muito alta, as taxas de infiltração variaram de 114 a $69 \mathrm{~mm} \mathrm{~h}^{-1}$, para as áreas com e sem dejeto, respectivamente. As APPs apresentaram solos arenosos com TIB variando de 210 a $384 \mathrm{~mm} \mathrm{~h}^{-1}$ em APPt e APPs, respectivamente. A técnica de manejo do solo utilizado na área agrícola, plantio direto ou fertirrigado, e as áreas com vegetação nativa, em solo sedimentar ou não, propiciaram a compactação e consequentemente, maior TIB no solo. 


\section{INTRODUÇÃO}

A velocidade de infiltração básica de água no solo (VIB) ou taxa de infiltração (TIB) é a velocidade com que a água se infiltra no solo através de sua superfície, sendo expressa por unidade indicativa de altura de lâmina d'água ou volume de água infiltrada em determinado perfil do solo por unidade de tempo (Brandão et al., 2006).

No manejo da irrigação, Bernardo et al. (2006) salienta que o conhecimento sobre a TIB do solo, influenciará na escolha do aspersor (TIB < Vazão do aspersor), assegurando o escoamento superficial, carreamento e lixiviação de nutrientes, desperdícios e de processos erosivos (Gondim et al., 2010).

A irrigação que utiliza o dejeto suíno como fonte de nutriente para o solo, possui alta concentração de sólidos, vindo a causar alteração na capacidade de infiltração da água no solo e o entupimento de micro e macro poros por conta do acúmulo de resíduos em sua superfície, acarretando no selamento superficial, e consequentemente, reduzindo a disponibilidade de água para as culturas agrícolas (Oliveira et al., 2000).

O manejo do solo possui forte influência na TIB e o não revolvimento do solo no sistema de plantio direto tende a ocasionar compactação do solo pelo tráfego intensivo de máquinas, o que pode diminuir consideravelmente a taxa de infiltração variando de acordo com o uso do solo (Mancuso et al., 2014), porém, o uso de tecnologias de precisão tende amenizar esse impacto ao solo.

O escoamento superficial é responsável por processos indesejáveis, como a erosão do solo e as inundações, logo, a infiltração determina o balanço de água na zona radicular e, por isso, o conhecimento desse processo e suas relações com as propriedades do solo são de fundamental importância para o eficiente manejo do solo e da água (Dalri et al., 2010).

De acordo com Souza e Alves (2003) a TIB é fundamental para a solução de problemas em áreas irrigadas, a conservação da água e do solo, controle do escoamento superficial, o entendimento do processo de infiltração, o manejo do solo e da água, e de suas relações com as propriedades do solo. Segundo Fuzer (2013) o conhecimento da TIB pode ser aplicado também em obras de engenharia como hidroelétricas, rodovias, reservatórios, lagos ornamentais, prevenção de enchentes, recuperação de áreas negativamente impactadas, descarte de efluentes fluviais urbanos e mapeamento de áreas de risco de alagamento.

Assim, esse trabalho teve como objetivo comparar a taxa de infiltração básica (TIB) de água no solo em uma área com e sem aplicação de dejeto suíno e em Áreas de Preservação Permanente em topo de morro (APPt) e próximo ao leito do rio (APPs), em propriedade agricultável no município de Rio Verde, Goiás.

\section{MATERIAL E MÉTODOS}

O trabalho foi realizado no município de Rio Verde, região Sudoeste do Estado de Goiás. O município possui área territorial de $8.386,827 \mathrm{~km}^{2}$, população estimada de 235.647 habitantes em 2019 (IDH, 2010) e densidade demográfica 28 hab. $\mathrm{km}^{-2}$.

Sua topografia é plana levemente ondulada com $5 \%$ de declividade, com altitude média de $748 \mathrm{~m}$. O solo de região é Latossolo Vermelho Escuro com texturas argiloso e areno-argilosa (Embrapa, 2009).

O clima (Inmet, 2020) apresenta duas estações bem definidas: uma seca (de maio a outubro) e outra chuvosa (novembro a abril). A temperatura média anual varia entre $20^{\circ} \mathrm{C}$ e $35^{\circ} \mathrm{C}$.

A vegetação é constituída de cerrado e matas residuais. Seu solo é do tipo Latossolo Vermelho Escuro com texturas argiloso e areno-argilosa (Embrapa, 2009), com clima predominante Tropical (Rio Verde, 2017).

A área de estudo está localizada na Rodovia Estadual Longitudinal, GO 174, km 10. Os locais de amostragem de solo foram áreas de preservação permanente em topo de morro (APPt), área de preservação permanente leito de rio (APPs), área de plantio direto com aplicação e sem aplicação de dejeto (Tabela 1 e Figura 1).

Tabela 01 - Localização dos pontos de amostragem da taxa de infiltração de água no solo.

\begin{tabular}{cccc}
\hline Localização & Altitude $(\mathbf{m})$ & Latitude & Longitude \\
\hline APPt & 745 & $17^{\circ} 56^{\prime} 37,53 " \mathrm{~S}$ & $50^{\circ} 58^{\prime} 7,76^{\prime \prime} \mathrm{O}$ \\
APPs & 672 & $17^{\circ} 54^{\prime} 56,31$ "S & $50^{\circ} 58^{\prime} 7,55^{\prime \prime} \mathrm{O}$ \\
Sem dejeto & 687 & $17^{\circ} 55^{\prime} 19,78^{\prime \prime} \mathrm{S}$ & $50^{\circ} 58^{\prime} 17,96^{\prime \prime} \mathrm{O}$ \\
Com dejeto & 667 & $17^{\circ} 55^{\prime} 28,22$ "S & $50^{\circ} 56^{\prime} 54,08^{\prime \prime} \mathrm{O}$ \\
\hline
\end{tabular}

Obs.: APPt: Área de Preservação Permanente em topo de morro; APPs: Área de Preservação Permanente em leito de rio. 


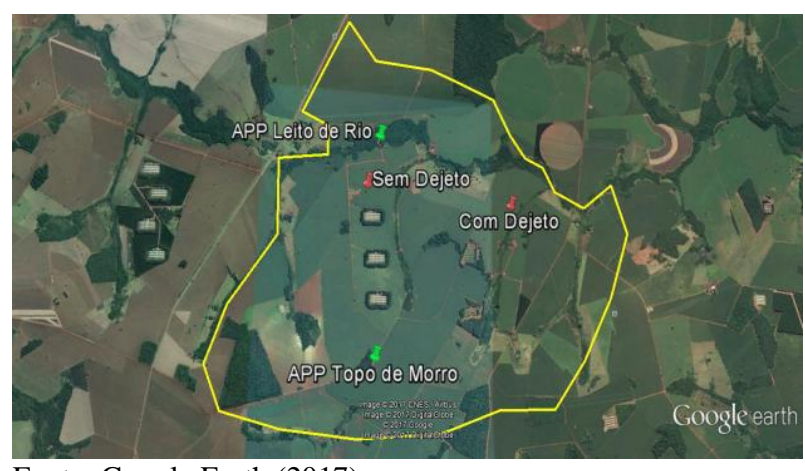

Fonte: Google Earth (2017)

Figura 1 - Distribuição dos pontos de amostragem da taxa de infiltração de água no solo.

A TIB foi determinada em setembro de 2016 e utilizou-se o método do infiltrômetro de anel, que consiste em dois anéis concêntricos, com diâmetro de $30 \mathrm{~cm}$ e $50 \mathrm{~cm}$, e altura de $35 \mathrm{~cm}$. Ambos foram fixados no solo até a aproximadamente de $5 \mathrm{~cm}$ de profundidade e realizou-se 3 repetições em cada área. O intervalo de leitura inicial foi de dois minutos na primeira hora e de cinco minutos nas próximas três horas restantes. Utilizou-se o modelo matemático de Kostiakov para representar a infiltração acumulada (Equação 1) e velocidade de infiltração de água no solo (Equação 2).

$$
\mathrm{I}=\mathrm{k} \cdot \mathrm{T}^{\mathrm{m}}
$$

(equação 1)

sendo:

$\mathrm{I}=$ infiltração de água no solo $(\mathrm{mm})$

$\mathrm{k}$ e $\mathrm{m}=$ coeficientes que dependem do solo (0-1)

$\mathrm{T}=$ tempo de infiltração acumulado (minutos)

sendo:

$$
\mathrm{VI}=\mathrm{m} \cdot \mathrm{k} \cdot \mathrm{T}^{\mathrm{m}-1 \quad \text { (equação } 2)}
$$

VI = velocidade instantânea de infiltração de água no solo (mm)

$\mathrm{k} \mathrm{e} \mathrm{m}=$ coeficientes que dependem do solo (0-1)

$\mathrm{T}=$ tempo de infiltração acumulado (minutos)

A velocidade de infiltração básica do solo pode ser classificada entre baixa a muito alta (Tabela 2). A textura do solo foi determinada a partir do método proposto pela Embrapa (2009) nos quatro pontos de coleta. As amostras foram retiradas nas profundidades 0-20, 20-40 e 40-60 cm.

Tabela 2 - Classificação da velocidade de infiltração de água no solo.

\begin{tabular}{cc} 
Solo de TIB muito alta & $30 \mathrm{~mm} \mathrm{~h}^{-1}$ \\
Solo de TIB alta & $15-30 \mathrm{~mm} \mathrm{~h}^{-1}$ \\
Solo de TIB média & $5-15 \mathrm{~mm} \mathrm{~h}^{-1}$ \\
Solo de TIB baixa & $<5 \mathrm{~mm} \mathrm{~h}^{-1}$ \\
\hline
\end{tabular}

Fonte: Bernardo et al. (2006).
As análises químicas do solo de cálcio, magnésio e sódio foram realizados para calcular a razão de adsorção do sódio (RAS), que é a proporção relativa de sódio em relação a outros sais (Equação 3).

$$
\mathrm{RAS}=\frac{\mathrm{Na}}{\sqrt{\frac{\mathrm{Ca}+\mathrm{Mg}}{2}}}
$$

sendo:

RAS = razão de adsorção do sódio

$\mathrm{Na}=$ sódio $\left(\mathrm{cmolc} \mathrm{dm}^{-3}\right)$

$\mathrm{Ca}=$ cálcio $\left(\mathrm{cmolc} \mathrm{dm}^{-3}\right)$

$\mathrm{Mg}=$ magnésio $\left(\mathrm{mg} \mathrm{dm}^{-3}\right)$

Segundo Daker (1984), os terrenos de planície baixa podem-se associar um valor médio da TIB com a textura do solo, sendo:

- $\quad$ solos de textura pesada - 5 a $12 \mathrm{~mm} \mathrm{~h}^{-1}$;

- solos de textura média - 12 a $20 \mathrm{~mm} \mathrm{~h}^{-1}$;

- solos arenosos leves - 20 a $40 \mathrm{~mm} \mathrm{~h}^{-1}$.

Este autor recomenda ainda que esses valores possam ser aumentados com adequada cobertura vegetais e diminuídos com o aumento da declividade do terreno. Analisou-se o teor de matéria orgânica e condutividade elétrica no dejeto suíno coletado na granja localizada na área de estudo. O dejeto suíno foi coletado na foz da lagoa de decantação. Uma amostra foi enviada ao Laboratório da Solotech em Rio Verde para realizar as análises seguindo a metodologia proposta pela Embrapa (2009).

\section{RESULTADOS E DISCUSSÃO}

As características de solo que apresentou maior alteração na textura em função da profundidade foi o que recebeu aplicação de dejeto suíno (Tabela 3). As áreas de cultivo em sistema de plantio direto, apresentaram perfil do solo mais argiloso e as áreas de APP argilo/arenoso.

$\mathrm{Na}$ área de cultivo fertirrigada, houve aumento do teor de argila em profundidade. A área de APPs por ser a jusante, recebe sedimentos carreados das áreas a montante. Devido à baixa influência do entorno, a área de APPt se manteve homogeneidade na textura entre as camadas de solo, exceto para a quantificação do teor de silte.

Áreas com características de solo arenoso, tendem a uma maior TIB em função da forma de agrupamento dos agregados, propiciando a maior quantidade de macroporos, sendo a resposta inversamente em solos argilosos. 
Houve baixas concentrações de cálcio, magnésio e sódio e consequentemente baixos valores de razão de adsorção de sódios (RAS) e tal comportamento pode coibir o desenvolvimento do sistema radicular de diversas culturas (Tabela 4).

Tabela 3 - Textura do solo em diferentes profundidades na área experimental.

\begin{tabular}{|c|c|c|c|c|}
\hline Profundidade $(\mathrm{cm})$ & & Textura & & \\
\hline $0-20$ & Argila (\%) & Silte (\%) & Areia (\%) & Classinicaçao \\
\hline Sem dejeto & 64 & 13 & 23 & Muito Argiloso \\
\hline Com dejeto & 37 & 51 & 12 & Franco Argiloso Siltosa \\
\hline $\mathrm{APPt}$ & 38 & 3 & 59 & Franco Argiloso Arenosa \\
\hline APPs & 13 & 6 & 81 & Areia Franca \\
\hline \multicolumn{5}{|l|}{$20-40$} \\
\hline Sem dejeto & 58 & 15 & 27 & Argila \\
\hline Com dejeto & 69 & 16 & 15 & Muito Argilosa \\
\hline $\mathrm{APPt}$ & 23 & 19 & 58 & Franco Arenosa \\
\hline APPs & 18 & 9 & 73 & Franco Arenosa \\
\hline \multicolumn{5}{|l|}{$40-60$} \\
\hline Sem dejeto & 62 & 17 & 21 & Muito Argiloso \\
\hline Com dejeto & 70 & 18 & 12 & Muito Argiloso \\
\hline $\mathrm{APPt}$ & 30 & 19 & 51 & Franco Argiloso Arenosa \\
\hline APPs & 21 & 7 & 73 & Franco Argiloso Arenosa \\
\hline
\end{tabular}

Tabela 4 - Caracterização química do solo em diferentes profundidades.

\begin{tabular}{ccccc}
\hline \multirow{2}{*}{ Elemento } & Local & \multicolumn{3}{c}{ Profundidade (cm) } \\
\cline { 3 - 5 } & Sem Dejeto & $0-20$ & $20-40$ & $40-60$ \\
\hline \multirow{2}{*}{$\mathrm{Ca}^{-3}$} & Com Dejeto & 2,34 & 1,82 & 1,88 \\
& APPt & 3,38 & 1,94 & 1,81 \\
& APPs & 1,91 & 1,60 & 1,41 \\
& Sem Dejeto & 1,46 & 1,37 & 1,70 \\
\hline \multirow{2}{*}{$\mathrm{Mg}$} & Com Dejeto & 0,22 & 0,08 & 0,10 \\
$\mathrm{cmolc} \mathrm{dm}^{-3}$ & APPt & 0,23 & 0,09 & 0,12 \\
& APPs & 0,40 & 0,19 & 0,08 \\
& Sem Dejeto & 0,16 & 0,06 & 0,17 \\
\hline \multirow{2}{*}{$\mathrm{Na}^{-3}$} & Com Dejeto & 8,0 & 7,0 & 7,0 \\
& APPt & 6,0 & 7,0 & 7,0 \\
& APPs & 6,0 & 6,0 & 6,0 \\
& Sem Dejeto & 0,42 & 7,0 & 7,0 \\
\hline \multirow{2}{*}{ Razão de Adsorção de Sódio (RAS) } & Com Dejeto & 0,36 & 0,44 & 0,43 \\
cmolc dm ${ }^{-3}$ & APPt & 0,33 & 0,42 & 0,43 \\
& APPs & 0,40 & 0,38 & 0,42 \\
& & & 0,50 & 0,43 \\
\hline
\end{tabular}

Com valores médios de condutividade elétrica acima de 4,6 $2,5 \mathrm{dS} \mathrm{m}^{-1}$, o uso do dejeto não influenciou na TIB do solo (Bernardo et al., 2006).

O descarte constante da água residuária de suíno na forma de fertirrigação, pode comprometer a TIB da área caso os valores de condutividade elétrica tendem a se elevar, principalmente cálcio e magnésio. Caso haja proporcionalidade no aumento na concentração do produto e determinador que determina a RAS, os riscos de redução da TIB, são menores.

Há alto teor de matéria orgânica e matéria seca no dejeto utilizado para fertirrigação (Tabela 5).
Tabela 5 - Análise do teor de matéria orgânica e matéria seca do dejeto utilizado na fertirrigação.

\begin{tabular}{cc}
\hline Elemento & Valor \\
\hline Matéria orgânica & $0,2 \mathrm{~g} \mathrm{~L}^{-1}$ \\
Matéria seca & $0,1(\%)$ \\
\hline
\end{tabular}

Considerando o suprimento da evapotranspiração da cultura média de $5 \mathrm{~mm} \mathrm{dia}^{-1}$ a partir do sistema de irrigação, a concentração de matéria orgânica disponibilizada no solo seria de $10 \mathrm{~kg} \mathrm{ha}^{-1}$. Dessa forma, na medida em que aumenta a matéria orgânica no solo aumenta também a TIB causando melhor troca catiônica no solo e assim favorecendo a penetração de água no solo. A aplicação constante de dejeto influencia na maior taxa de infiltração. 
A taxa de infiltração e infiltração de água no solo foi de 114 a $69 \mathrm{~mm} \mathrm{~h}^{-1}$ e 592 a $267 \mathrm{~mm} \mathrm{~h}^{-1}$, para a área fertirrigada com dejeto suíno e área de lavoura com plantio direto, respectivamente (Figuras 2 e 3 ).

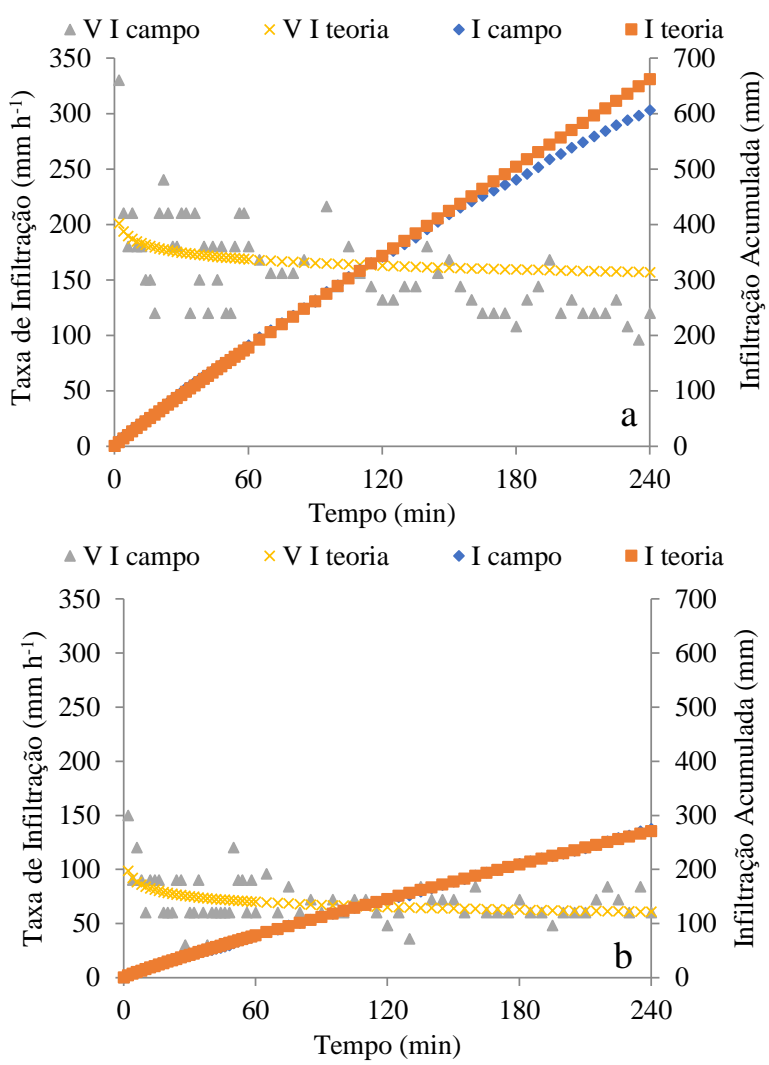

Figura 2 - Taxa de infiltração em área fertirrigada com dejeto suíno (a) e lavoura com plantio direto (b).

Resultados semelhantes foram obtidos Dalri et al. (2010). As elevadas taxas de infiltração de água no solo de ambas as áreas avaliadas (Figura $2 \mathrm{a}$ e b) foi devido a aplicação de dejetos (matéria orgânica) na área com irrigação e material de cultivo em decomposição. Na propriedade estudada é utilizado a

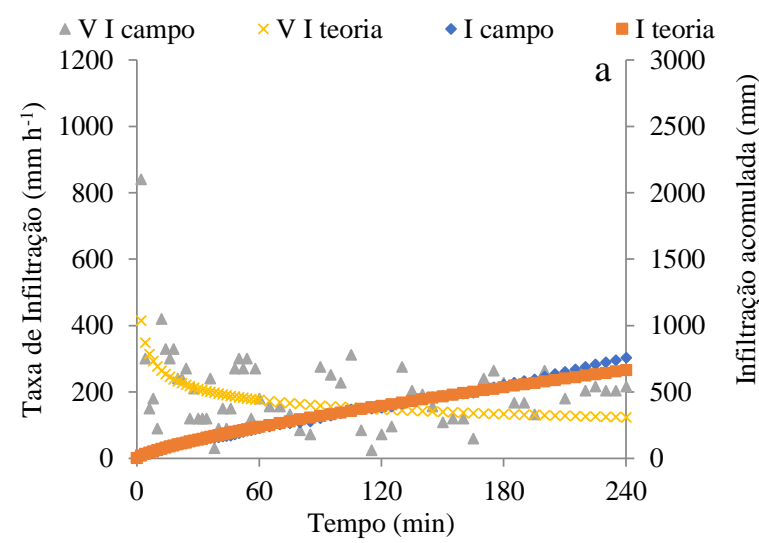

prática de plantio direto e fertirrigação de dejeto a mais de vinte anos favorecendo na alta infiltração do solo. As elevadas taxas de infiltração de água no solo favorecem a retenção de água no solo, recarregando o lençol freático e reduzindo o escoamento

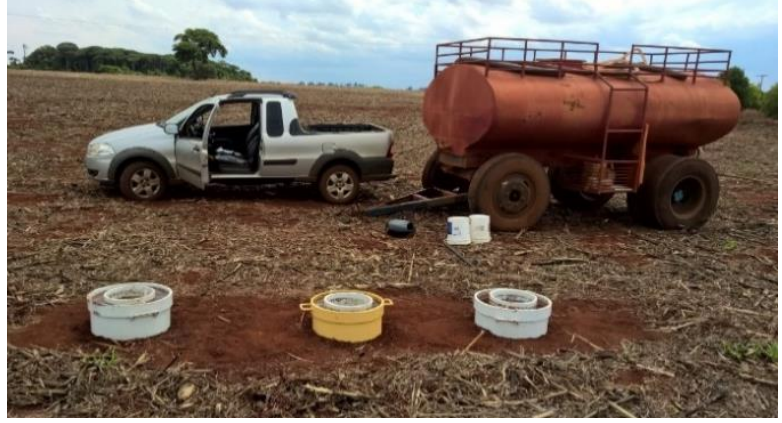

superficial.

Figura 3 - Determinação da taxa de infiltração de água no solo em área de plantio.

A redução do escoamento superficial foi devido a maior taxa de infiltração o que provavelmente favoreceu na conservação dos mananciais e reduziu a quantidade de sedimentos que são carreados para os mesmos. Alves Sobrinho et al. (2003) obtiveram maiores valores de TIB com o sistema de plantio direto em relação ao preparo convencional e entre os tratamentos estudados a sucessão soja e aveia. Fuzer (2013) verificou em seu estudo duas TIB's elevadas, sendo estas com índices de 92,2 e 107,52 $\mathrm{mm} \mathrm{h}^{-1}$, ambos TIB's em solos arenosos leves, dados estes que corroboram com os encontrados neste trabalho, porém em área com solo argiloso.

A taxa de infiltração e a infiltração acumulada apresentadas nas Figuras 4 e 5 demonstram os valores de infiltração básica de 210 a $384 \mathrm{~mm} \mathrm{~h}^{-1} \mathrm{e} 732$ a $2.180 \mathrm{~mm} \mathrm{~h}^{-1}$, para a APPs e APPt, respectivamente (Tabela 6). As condições de relevo, sendo a APPt mais plana, favoreceram para a maior retenção de água.

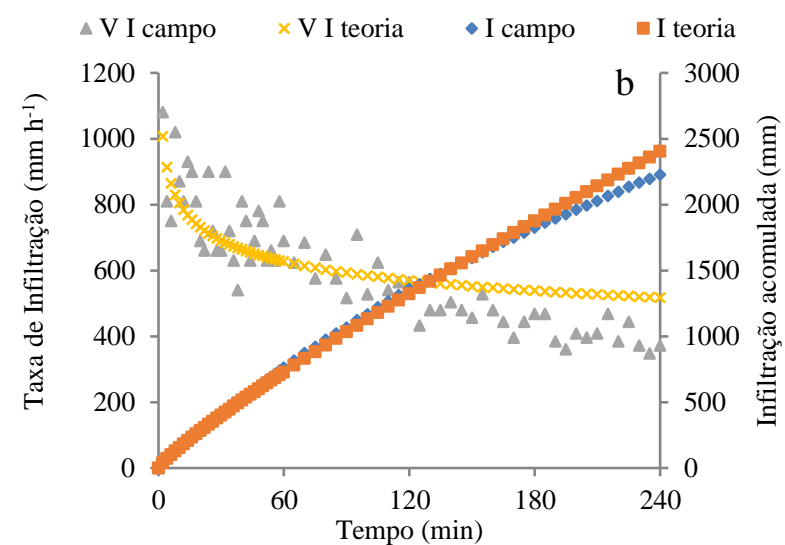

Figura 4 - Velocidade de infiltração de água no solo em área de preservação permanente leito do rio (a) e em áreas de preservação permanente topo de morro (b). 


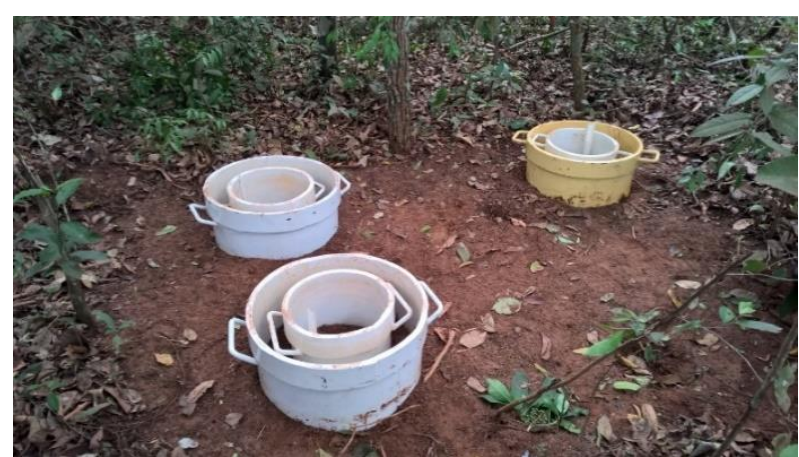

Figura 5 - Determinação da velocidade de infiltração de água no solo em área de preservação permanente.

A alta taxa de infiltração nas áreas de APP (Figura 4 a e b), é justificada devido ao adensamento da concentração de raízes das árvores e matéria orgânica das folhas que propicia na maior retenção de água ao solo. As condições de solo das matas virgens em condições solo arenoso, favorece a penetração de água, auxiliando na recarga dos aquíferos e abastecimento dos mananciais.

Resultados semelhantes foram obtidos por Gonçalves et al. (2015) com valores de TIB muito alta $\left(750 \mathrm{~mm} \mathrm{~h}^{-1}\right)$ em solo arenoso, obtendo valores maiores que ambas as análises apresentadas (Tabela 3). Os solos são considerados franco arenosos os quais retém menos água que o solo arenoso. Conforme Fuzer (2013), em seu estudo obteve uma taxa de infiltração de $107 \mathrm{~mm} \mathrm{~h}^{-1}$ e $92 \mathrm{~mm} \mathrm{~h}^{-1}$, por ter solos arenosos em ambas às áreas, com teor de matéria orgânica elevados, sendo solos bem escuros, obtendo resultados parecidos com as áreas de APPt e APPs que possuem teor elevado de matéria orgânica.

Tabela 6 - Modelos de taxa de infiltração e infiltração acumulada de água no solo na área experimental.

\begin{tabular}{cccc}
\hline Local & Modelo & IA $(\mathrm{mm})$ & TIB $\left(\mathrm{mm} \mathrm{h}^{-1}\right)$ \\
\hline \multirow{3}{*}{ Sem desejo } & Modelo de Kostiakov & $1,9643 \cdot \mathrm{T}^{0,8988}$ & $0,8988 \cdot 1,9643 \cdot \mathrm{T}^{(0,8988-1)} \cdot 60$ \\
& Valores de campo & 267 & 69 \\
& Valores teóricos & 263 & 61 \\
\hline \multirow{3}{*}{ Com desejo } & Modelo de Kostiakov & $3,6509 \cdot \mathrm{T}^{0,9487}$ & $0,9487 \cdot 3,6509 \cdot \mathrm{T}^{(0,9487-1) \cdot 60}$ \\
& Valores de campo & 592 & 114 \\
& Valores teóricos & 642 & 157 \\
\hline \multirow{2}{*}{ APPs } & Modelo de Kostiakov & $11,03316 \cdot \mathrm{T}^{0,7473}$ & $0,7473 \cdot 11,03316 \cdot \mathrm{T}^{(0,7473-1) \cdot 60}$ \\
& Valores de campo & 732 & 210 \\
\hline \multirow{2}{*}{ APPt } & Valores teóricos & 647 & 125 \\
& Modelo de Kostiakov & $11,9344 \cdot \mathrm{T}^{0,9932}$ & $0,9932 \cdot 11,9344 \cdot \mathrm{T}^{(0,9932-1) \cdot 60}$ \\
& Valores de campo & 2.180 & 384 \\
\hline
\end{tabular}

Obs.: IA: Infiltração acumulada; TIB: Taxa de infiltração de água no solo.

A determinação da TIB auxilia em várias etapas do manejo hidrológico, agrícola e ambiental. Além disso, o modelo de Kostiakov foi fundamental para auxiliar na determinação da taxa de infiltração e consequentemente no escoamento superficial. Os modelos obtidos para a área experimental foram muito próximos dos obtidos em campo.

\section{CONCLUSÕES}

As áreas irrigadas se caracterizou com solo argiloso e TIB muito alta, variando de 114 a $69 \mathrm{~mm}$ $\mathrm{h}^{-1}$, para as áreas com e sem dejeto, respectivamente. As APPs com solos arenosos a TIB variou de 210 a $384 \mathrm{~mm} \mathrm{~h}^{-1}$ em APPt e APPs, respectivamente. A técnica de manejo do solo utilizado na área agrícola, plantio direto ou fertirrigado, e as áreas com vegetação nativa, em solo sedimentar ou não, propiciaram a compactação e consequentemente, maior TIB no solo.

\section{REFERÊNCIAS BIBLIOGRÁFICAS}

Alves Sobrinho T, Vitorino ACT, Souza LCF, Gonçalves MC, Carvalho DF. de. Infiltração de água no solo em sistemas de plantio direto e convencional. Revista Brasileira de Engenharia Agrícola e Ambiental, v.7, n.2, p.191-196, 2013.

https://doi.org/10.1590/10.1590/S14154366200300020000 1

Bernardo S, Soares AA, Mantovani EC. Manual de irrigação. 8. ed. Viçosa: UFV, 2006. 625 p.

Brandão VS, Cecílio RA, Pruski FF, Silva DD. Infiltração de água no solo. 3 ed. Atual e Ampl. Viçosa: UFV, 2006a. 120 p.

Daker A. Irrigação e drenagem: A água na agricultura. 6 ed. Rio de Janeiro, 1984.

Dalri AB, Cortez GEP, Riul LGS, Araújo JAC, Cruz RL. Influência da aplicação de vinhaça na capacidade de infiltração de um solo de textura franco arenosa. Irriga, v.15, n.4, p.344-352, 2010. https://doi.org/10.15809/irriga.2010v15n4p344 
Dartora V, Perdomo CC, Tumelero IL. Manejo de dejetos suínos. Articulação da Embrapa Suínos e Aves com a Associação Riograndense de Empreendimentos de Assistência Técnica e Extensão Rural - EMATER/RS. 1998.

Empresa Brasileira De Pesquisa Agropecuária - EMBRAPA. Centro Nacional de Pesquisa de Solos. Sistema brasileiro de classificação de solos. 2.ed. Rio de Janeiro, 2009.

Fuzer H. Estudo da velocidade de infiltração básica (vib) no solo da bacia do Rio Mourão. Universidade Tecnológica Federal do Paraná Campus Campo Mourão Diretoria de Graduação e Educação Profissional Coordenação de Engenharia Civil. Trabalho de Conclusão de Curso 2013.

Gonçalves AA, Sousa EF, Lima IS, Salazar RC, Gomes Filho, RR. Determinação da velocidade de infiltração básica da água no neossolo por meio de anéis de concêntricos na área experimental da UFS. XXV CONIRD - Congresso Nacional de Irrigação e Drenagem. Anais 08 a 13 de novembro de 2015, UFS - São Cristóvão/SE.

Gondim TMS, Wanderley JAC, Souza JM, Feitosa Filho JC, Souza JS. Infiltração e velocidade de infiltração de água pelo método do infiltrômetro de anel em solo arenoargiloso. REBAGA, v.4, n.1, p. 64-73 2010.

Índice De Desenvolvimento Humano. Programa das Nações Unidas para ao Desenvolvimento. 2020. Disponível em: <https://www.br.undp.org>. Acesso em: 05 jan 2020.

Instituto Nacional De Meteorologia. Dados climáticos. Disponível em: <http://www.inmet.gov.br/portal/>. Acesso em: 05 jan 2020.

Mancuso MA, Flores BA, Rosa GM, Schroeder JK, Pretto PRP. Características da taxa de infiltração e densidade do solo em distintos tipos de cobertura de solo em zona urbana. Revista Monografias Ambientais, v.14, n.1, Edição Especial p.2890-2998, 2014. https://doi.org/10.5902/2236130810932

Miranda CR, Zardo AO, Gosmann HA. Uso de dejetos de suínos na agricultura. Empresa Brasileira de Pesquisa Agropecuária. Centro Nacional de Pesquisa de Suínos e Aves. 1999.

Oliveira RA, Gonçalves PL, Matos AT, Martinez MA, Cecon, P.R. Influência da aplicação de águas residuárias de suinocultura na capacidade de infiltração de um solo podzólico vermelho-amarelo. Revista Brasileira de Engenharia Agrícola e Ambiental, v.4, n.2, p.263-267, 2000. https://doi.org/10.1590/S1415-43662000000200022

Rio Verde, Prefeitura. Secretaria de Comunicação de Rio Verde GO, 2017.

Souza ZM, Alves MC. Movimento de água e resistência à penetração em um Latossolo Vermelho distrófico de cerrado, sob diferentes usos e manejos. Revista Brasileira de Engenharia Agrícola e Ambiental, v.7, n.1, p.18-23, 2003. https://doi.org/10.1590/S1415-43662003000100004 